\title{
La colección de un autor y su conservación (el caso Dalí)
}

Georgina Berini Aytés

\author{
Jefa del Departamento de Conservación y \\ Restauración \\ Fundación Gala-Salvador Dali. Figueres
}

\section{Resumen}

La conservación de la obra de un autor, en el caso de la de Salvador Dalí, presenta unos problemas peculiares derivados de la multiplicidad de recursos utilizados por Dalí y de las circunstancias que rodean su exhibición, especialmente en el Teatro-Museo Dalí de Figueres.

Este artículo muestra esta problemática y las soluciones aplicadas por el Departamento de Conservación y Restauración de la Fundación Gala Salvador Dalí, tanto en el ámbito general como en los tipos de obras más características: pinturas y montajes.

Se muestran ejemplos de conservación preventiva de tipo general, como el control climático de las zonas de exposición y el sistema de presentación de las obras, así como ejmplos de intervención en algunas obras. Ejemplos que, en el caso de la pintura, pueden abarcar desde la mínima intervención hasta propuestas no convencionales.. En el caso de los montajes, se muestran ejemplos de intervenciones en obras de interior y de exterior, dados los diferentes condicionamientos técnicos.

\section{Palabras clave}

Teatro-Museo Dalí / Fundación Gala-Salvador Dalí / Conservación / Prevención

\section{Introducción}

La conservación de la obra de un autor goza, a diferencia de la de una colección de múltiples autores, de la aparente ventaja de la unidad técnica o temática que se supone al trabajo de un artista. En el caso de Salvador Dalí, sin embargo, contamos con la obra de uno de los artistas más variados, intensos y extensos del siglo $X X$, que, a lo largo de cerca de 70 años de actividad incesante, realizó no sólo un gran número de pinturas de las más variadas técnicas, sino toda clase de objetos, montajes e instalaciones, tal como reflejan los espacios de exposición gestionados por la Fundación Gala-Salvador Dalí, entidad creada por el propio artista el 1983 para "promocionar, fomentar, divulgar, prestigiar, proteger y defender" su obra. Actualmente la Fundación Gala-Salvador Dalí (FGSD), además del Teatro-Museo Dalí de Figueres, mantiene abiertas al público la casa del artista en Port Lligat (Cadaqués, Girona) y el castillo de Púbol (La Pera, Girona), que Dalí regaló a Gala en los años setenta.

A pesar de la visión comúnmente aceptada de Dalí como pintor, lo cierto es que era un artista que, desde sus inicios, utilizó y experimentó con gran variedad de procedimientos y materiales, además de reflejar en abundantes escritos sus reflexiones sobre la práctica artística. Afortunadamente no faltan criterios emanados del propio autor para dar sentido a las tareas de conservación y restauración de su obra.

Dalí es uno de los paradigmas del arte contemporáneo en su afán de fundir el arte con la vida, en su pretensión de dar sentido artístico a todos los espacios, a todos los tiempos: así, su Teatro-Museo de Figueres no es un contenedor de la obra de un pintor, sino que fue concebido por Dalí como una gran instalación, como un montaje que, más que recoger obra, fuera "la obra"; su casa de Port Lligat fue escenario de constantes "happenings" y cambiantes montajes e instalaciones; dio su particular toque surrealista a la decoración del castillo de Púbol; y antes de trasladarse a su última residencia en la Torre Galatea, se aseguró que la decoración exterior del edificio tuviera su sello personal, coronándolo con múltiples esculturas en forma de huevo y de maniquíes, y adornando la fachada con centenares de panes típicos de Figueres. 
El caso del Teatro-Museo Dalí es particularmente interesante para hacernos reflexionar, desde el punto de vista de la conservación, sobre la relatividad de las estadísticas sobre los museos más visitados.

En este edificio anexo al Teatro-Museo, bautizado por Dalí como torre Galatea en homenaje a Gala, vivió el artista los últimos años hasta su muerte en 1989, y tiene su sede la FGSD, en la que, en 1985, fue creado el Departamento de Conservación y Restauración, cuya actividad específica se centra en tres ámbitos:

$I^{\circ}$. el de la Conservación, realizando el seguimiento periódico y el mantenimiento general de los 3 museos, efectuando la limpieza de las obras y objetos, el control climático, y parte de las desinfecciones, y desarrollando una política de prevención contra el desgaste propio del uso y del tiempo.

$2^{\circ}$. el de la Restauración, que en la actualidad, salvo pocas excepciones, tras 15 años de intervenciones prioritarias a la obra pictórica, se reduce en general a "puestas a punto" de las pinturas para poder ser exhibidas o prestadas, y se enfoca cada vez más hacia la restauración de objetos, montajes e instalaciones.

$3^{\circ}$. el de la Investigación, estudiando los numerosos y sorprendentes recursos técnicos de S. Dalí, sobre los que aún no existe ningún estudio serio, y cuyo conocimiento es imprescindible antes de intervenir sobre cualquier obra, así como para la correcta catalogación de los fondos de la Fundación, y para poder aportar argumentos decisivos en las autentificaciones de obras. Para ello, contamos con la colaboración de los laboratorios científicos de los Departamentos de Conservación y Restauración del C.A.R.S. en Madrid, y de la Facultad de Bellas Artes de la Universidad de Barcelona, con los que se están realizando estudios sobre la técnica pictórica, y la obra gráfica de Dalí.

Paralelamente a estas tareas, es también desde este Departamento que se responde a las eventualidades, cada vez más frecuentes, como son las exposiciones temporales (elaboración de fichas de estado de conservación de las obras, enmarcaciones, con- trol de embalajes, correos...) o el montaje material de exposiciones organizadas por la Fundación. Este tipo de actividades puntuales tiene un carácter prioritario sobre cualquier actividad programada del Departamento.

Es también responsabilidad del Departamento de Conservación y Restauración, dada la complejidad de la obra a tratar y las limitaciones inevitables de personal, la coordinación de colaboraciones externas para otras especialidades, como son la restauración de papel, de muebles y objetos de madera, de taxidermias, de tejidos, así como el control de la realización de copias de originales, ya sea por fotógrafos para las obras bidimensionales, o por "tematizadores", para objetos, montajes e instalaciones. (entendemos por tematizadores un tipo de profesionales -cuyo nombre proviene de su trabajo en la construcción de parques temáticos- dedicados a la recreación de todo tipo de objetos y ambientes, siendo una actualización del tradicional oficio de los escenógrafos, decoradores, "atrezzistas", etc.).

\section{Criterios de conservación}

La filosofía del Departamento de Conservación y Restauración ha sido, desde sus comienzos, la de intentar resolver los problemas de conservación de las obras a partir del conocimiento de sus causas: así, además de las inevitables intervenciones de restauración, se ha ido desarrollando una política de prevención para atenuar, en lo posible, las causas externas de degradación de las obras.

Esta política se ha basado en informar a los órganos directivos de la Fundación, a través de informes técnicos de ciertas obras restauradas, exponiendo las causas externas de su deterioro y proponiendo medidas preventivas. El primer informe se remonta a 1985, después de la restauración de Port Alguer, óleo sobre tela de $100 \times 100 \mathrm{~cm}$., pintado en 1924, y exhibido en la Sala del Tesoro 
del Teatro-Museo, solicitando que esta obra no fuera devuelta a su sala en las mismas condiciones en que estaba antes de la restauración: con un marco consistente en cuatro listones de madera clavados al bastidor, que impedían cualquier tensado de la tela, sin protección anterior ni posterior, en una sala de pequeñas dimensiones normalmente abarrotada de público, y dotada de una anticuada máquina de aire acondicionado manipulada por el vigilante de turno según su particular percepción térmica.

El contenido de este informe tuvo el privilegio de llegar directamente a Dalí, quién encargó, con intuición y lucidez, un marco-vitrina de roble, prácticamente hermético, con el fondo forrado con el mismo terciopelo que las paredes de la sala: su propuesta estética era perfectamente compatible con nuestras condiciones de conservación, otorgando a la obra una protección y un microclima particular, gracias a que el terciopelo actuaba como "material-tampón", atenuando en el interior de la vitrina las variaciones externas de humedad relativa.

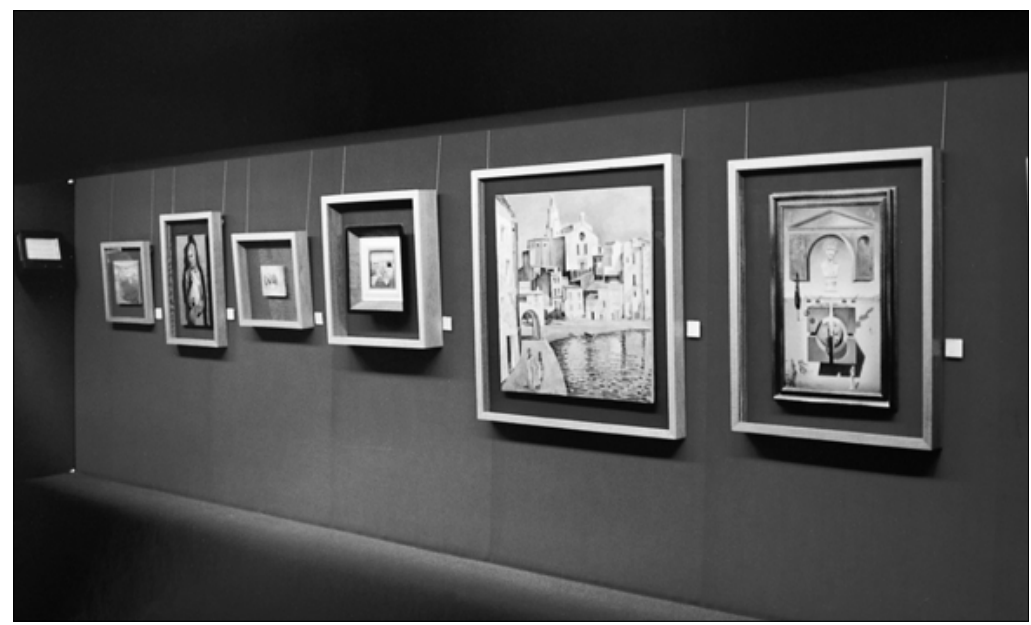

I. Sistema de presentación "daliniano" de los cuadros en la Sala del Tesoro ("Port Alguer" es el segundo, empezando por la derecha).
Esta anécdota, ya histórica, nos da la primera clave en que se basan nuestros criterios de conservación: conocer y respetar la voluntad del artista. A partir de la muerte de Dalí, en 1989, nuestros sucesivos informes técnicos, explicando ciertas degradaciones de las obras de Dalí a partir de causas ambientales, han ido propiciando un gran número de mejoras en el Teatro-Museo, en el sistema de presentación de las obras e, incluso, en la política de préstamos. Así pues, nuestra segunda clave es la prevención, con el control de los factores de degradación externos de las obras, y bajo el lema de "Conservar al máximo, para restaurar lo mínimo".

Por fin, cuando es inevitable la intervención, nuestros criterios pueden abarcar desde una restauración convencional para obras convencionales, hasta la sustitución de una obra por una copia, pasando por un sinfín de intervenciones singulares para casos especiales. En el último apartado de este artículo, dedicado a criterios de intervención, se exponen ejemplos de cada caso.

\section{Análisis de los factores de degradación y criterios de conservación preventiva}

Hemos distinguido diferentes causas de degradación de la obra de Salvador Dalí, en función de sus características:

3.I. las que afectan al conjunto de su gran obra, el Teatro-Museo Dalí, y que son, su situación geográfica con su particular clima, el edificio del museo, cuyas características son las de un teatro; y por fin, la influencia del público y los horarios de apertura.

3.2. las que afectan a su obra pictórica, en función de su calidad técnica y de la historia de sus movimientos.

3.I.I. El primer factor de degradación viene dado por la zona geográfica en que está ubicado el Teatro-Museo: la llanura del Ampurdán, al norte de Cataluña, tiene un clima mediterráneo, de inviernos suaves y veranos calurosos, y se asienta en un terreno de origen pantanoso, lo que favorece un alto índice de humedad relativa en general; desgraciadamente, la otra característica de esta zona es el factor sorpresa de la tramontana, viento del norte que en pocas horas puede hacer bajar esta humedad alrededor de 50 puntos porcentuales, afectando bruscamente la estabilidad de ciertos materiales de que están compuestas las obras, como la madera, el papel, algunos lienzos...

Estas enormes fluctuaciones de la humedad relativa exterior han afectado considerablemente el clima del museo durante 20 años, desde su inauguración, hasta que en 1994 se instala por fin un sistema de control climático general dirigido desde un ordenador central, cuyos efectos benefactores quedan registrados en las gráficas de los termo-higrógrafos de cada sala: cuando en el exterior la humedad relativa baja en picado alrededor de 50 puntos porcentuales, en el interior de las salas sólo se registran descensos entre 8 y 12 puntos porcentuales, según su situación en el edificio.

3.I.2. El segundo factor de degradación, lo constituye el propio edificio del Teatro-Museo, ya que, por un lado, tiene las condiciones de un teatro, y por el otro, Dalí lo concibe como una sola obra: ya en 1961, en un primer acto de presentación del proyecto, Dalí realizó estas sorprendentes declaraciones:

"El teatro es un lugar predestinado para un museo Dalí... el estado del local es maravilloso; nada se tiene que arreglar ni restaurar. Cada centímetro de estas paredes llenas de mierda es un cuadro abstracto. Marcel Duchamp, que está en Cadaqués, ha dicho que con este museo cada abstracto tendrá alguna cosa que escoger que responda a su trágico destino personal. Será el único museo surrealista del mundo. No habrá ninguna obra original. En los ventanales destruidos instalaré fotos inmensas de todos mis cuadros... juego con suerte: como que detrás del teatro hay la pescadería, abriré grandes ventanales e 
instalaré cristales porque de esta forma se podrá contemplar a gusto esta orgía homérica sublime que es un mercado de pescado... la gente no saldrá decepcionada: las fotos tienen una ventaja: son mejores que la obra original. ¡Ya se decepcionarán cuando vean los cuadros!"

A pesar del susto que se llevaron las autoridades con estas intenciones tan poco convencionales, y después de no pocas dificultades, el Teatro-Museo Dalí fue inaugurado el 28 de septiembre de 1974, conteniendo obras originales de su colección, y montajes e instalaciones hechos expresamente, que el artista fue aumentando y modificando con el tiempo.

El Teatro-Museo Dalí, instalado en el edificio en ruinas del antiguo teatro municipal de Figueres, semidestruído durante la guerra civil, conserva su estructura de teatro clásico "a la italiana", en la que el artista hizo una labor de rediseño: coronó el escenario con una gran cúpula geodésica, obra del arquitecto Emilio Pérez Piñero, consistente en una estructura de aluminio que soportaba una serie de triángulos de metacrilato. Las grandes variaciones de temperatura y de humedad relativa no podían ser atenuadas por la débil protección de los metacrilatos que, desde 1974 iban deteriorándose, y la Sala de la Cúpula, por sus dimensiones y condición era inclimatizable, hasta que, en 1999, se decide una intervención drástica: la sustitución de la cúpula original, de aluminio y metacrilato, por otra igual, pero de acero inoxidable y cristales dobles.

El cambio de cúpula ha representado un gran avance en el aislamiento térmico de una buena parte del Museo, y, aunque ha mejorado el aislamiento lumínico, no se pueden rebajar los más de 40.000 lux al mediodía, en pleno sol, por lo que las medidas de prevención de las obras de esta sala contemplan criterios aún más drásticos, como la sustitución de originales por reproducciones fotográficas, siguiendo la vía abierta por el propio Dalí con "El Torero alucinógeno", óleo de $400 \times 300 \mathrm{~cm}$. que pintó entre 1968 y 1970, propiedad del matrimonio Morse, fundadores del Dalí Museum de Florida. Dalí instaló su reproducción fotográfica sobre tela a escala I:I a una altura que impide al espectador apreciar si se trata de una pintura o no, pero que le permite gozar con su propuesta conceptual y lúdica de la doble imagen.

En esta misma sala, antiguo escenario del teatro, encontramos, lógicamente, un gran telón de fondo, a partir de una maqueta pintada por Dalí en 194I para una obra de teatro titulada Laberinto. Pintura al temple sobre una lona de $880 \times 1300 \mathrm{~cm}$, realizada por su ayudante de taller, esta obra resiste con dignidad sus condiciones de exposición, así como el paso de los años. Dalí la hizo proteger ilusamente con un baldaquino de terciopelo, y parece coherente que, en un caso de deterioro extremo, volvería a encargar un nuevo telón a partir de su maqueta a algún especialista.

Las paredes de la Sala de la Cúpula están decoradas por personajes pintados en los años setenta, al óleo
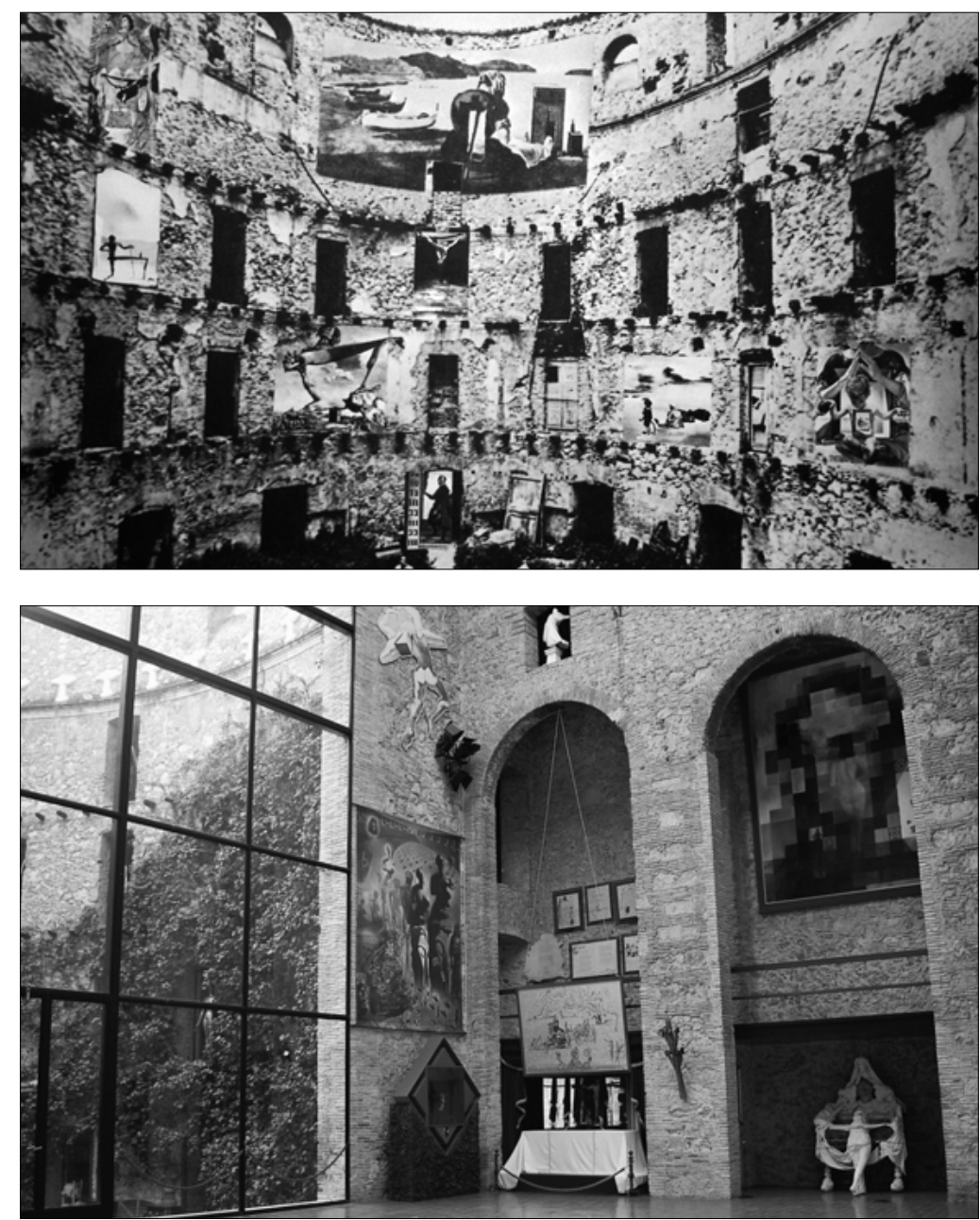

sobre papel de embalar. Dalí los presentó recortados sobre un fondo de madera y un metacrilato en contacto directo con la pintura. En 1992, estas obras originales, o lo que quedaba de ellas, fueron sustituidas por reproducciones fotográficas a la misma escala, restauradas y exhibidas en una sala con condiciones climáticas y lumínicas adecuadas. Por supuesto, estas fotografías deben reponerse más o menos cada dos años, a causa de su degradación por causas lumínicas.

El Retrato de Lincoln, o más precisamente, "Gala mirando el mar Mediterráneo, que, a una distancia de 20 metros, se transforma en el retrato de Abraham Lincoln. (Homenaje a Rothko)", fue pintado entre 1974 y 1975 a partir de una interpretación digital de una foto de este personaje, obtenida por el cibernético León D. Harmon. En 1976, Dalí realiza una segunda versión para su Teatro-Museo, pintando al óleo un cartón fotográfico con su reproducción ligeramente ampliada $(420 \times 318 \mathrm{~cm})$.

Esta obra presenta serios problemas de conservación, ya que está encolada sobre un tablero de madera que responde a las variaciones de humedad relativa (inevitables en este espacio del museo) de distinta forma que el cartón fotográfico, provocándole tensiones y roturas en unos puntos determinados. Su sustitución por una reproducción está en suspen-
2. Tanto en sus declaraciones, como en este fotomontaje de 1961, realizado por Dalí sobre una foto de las "ruinas" del patio de butacas, constatamos que el artista no es contrario a las reproducciones fotográficas.

3. Vista parcial de la Sala de la Cúpula, donde se puede apreciar en la pared de la cristalera que da al patio, al "Torero alucinógeno", debajo de las reproducciones de unos ángeles sobre papel de embalar. En el pasillo del primer piso, el Retrato de Lincoln. 
so hasta que podamos programar hacer "in situ" la delicada operación de desencolar el cartón del soporte de madera, ya que éste no pasa por ninguno de los accesos a la Sala de la Cúpula. Debido a que sólo hay dos meses al año con relativamente pocos visitantes, esta actuación sólo se puede programar durante enero y febrero, y hasta el momento, no la hemos podido incluir en nuestro calendario.

Desde la Sala de la cúpula se accede a otra zona emblemática del Museo: Dalí "conservó" el antiguo patio de butacas como un gran patio al cielo abierto, tal como había quedado después de la guerra: "i...una sola bomba fue la que hizo mi museo! ¡Un verdadero Ready Made!", exclamaría.

Se trata, en su conjunto, de una gran instalación presidida por su último gran assemblage, que compuso por etapas, primero, con el taxi lluvioso, al que, posteriormente, dotó, a modo de enorme tapón del radiador, con la escultura de la reina Esther del artista austríaco Ernst Fuchs. En homenaje a Gala, después de su muerte, culmina su obra encadenando la reina Esther a la barca de Gala, con un paraguas en el mástil, chorreando agua de mar de poliéster, y sostenida por la reproducción pintada de negro del esclavo de Miguel Angel, ayudado por dos gigantescas muletas y colocado encima de una columna de 32 neumáticos de tractor horizontales coronados por 2 verticales que enmarcan un busto original de François Girardon.

$\mathrm{Ni}$ que decir tiene que este "assemblage" requiere un riguroso mantenimiento, y ha sido objeto a lo largo de los años de numerosas restauraciones que comentaremos en el apartado dedicado a criterios de intervención.

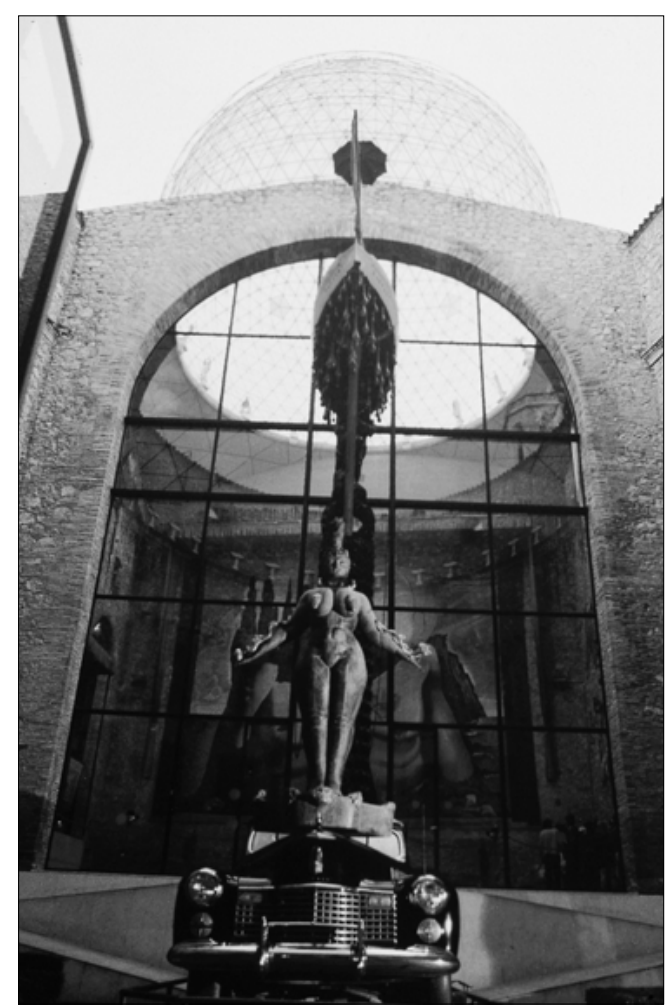

Desde el patio, accedemos a la zona climatizada del edificio, con los antiguos pasillos que conducían a los palcos convertidos en largas y estrechas salas de exposición, con numerosas ventanas que dan al patio, y que fueron selladas a petición nuestra con el fin de reducir alteraciones en el clima; igualmente, los cristales fueron laminados con films con filtro para los rayos ultravioletas. Aún con todo, en los pasillos sólo se exhibe obra gráfica, así como montajes protegidos dentro de vitrinas.

La antigua sala de descanso del teatro, bautizada "Palau del Vent", cuyo techo está cubierto por una gran pintura, es un híbrido entre instalación y sala convencional de exposición de pinturas, dibujos y esculturas.

Por fin, cinco salas fueron destinadas a la exposición de pinturas, sin orden lógico ni cronológico. Cuatro de ellas tienen las paredes forradas de terciopelo según el diseño del artista, y, como cada espacio climatizable del museo, cada una está controlada con un termo-higrógrafo. (ver F.I.).

De las dos salas restantes en el edificio, las dos conteniendo mayoritariamente montajes, cabe destacar la Sala de Mae West, gran instalación con la reproducción tridimensional (realizada por el arquitecto Oscar Tusquets) a partir de la manipulación de una fotografía del rostro de Mae West que Dalí realizó con "gouache" en 1934, y que nos servirá de introducción al tercer factor externo de degradación: el público.

3.I.3. El espectacular y mantenido número de visitantes que atrae la obra de Dalí permite unos balances largamente positivos en el estado de cuentas de la FGSD, además de colmar las expectativas del artista. Con la creación de su museo en su ciudad natal, Dalí manifestó su intención de convertirla en la Meca del arte moderno. Progresivamente hasta hoy, su deseo parece acercarse a la realidad, puesto que por la afluencia de público, el Teatro-Museo Dalí es uno de los más visitados de España, a pesar de estar ubicado en una ciudad de 36.000 habitantes, que se encuentra a $150 \mathrm{Km}$ de Barcelona, y a 750 de Madrid.

El día de la inauguración, acudieron 2.000 personas, y esta cantidad no ha hecho sino incrementarse. Estos datos que, desde el punto de vista económico resultan tan halagüeños, y que Dalí celebraba con la tópica frase "el éxito ha sorprendido a la propia empresa", constituyen, sin embargo, una de las causas de degradación de su obra: es importante recordar cómo la cantidad de personas en un espacio cerrado influye en las condiciones climáticas del mismo, y que la alteración de ciertos parámetros de temperatura y humedad relativa pueden afectar los materiales de que están compuestas las obras de arte: por un lado, dilataciones o encogimientos de soportes de tela o papel y, más dramáticamente, en la madera, provocando descohesiones de la capa

pictórica.
4. Vista del patio con su gran mblage", y al fondo, la Sala de la Cúplula, con el telón de "e laberinto". 
El caso del Teatro-Museo Dalí es particularmente interesante para hacernos reflexionar, desde el punto de vista de la conservación, sobre la relatividad de las estadísticas sobre los museos más visitados: cuando nos dicen que el número de visitantes anual del Teatro-Museo supera los 750.000, lo único que podemos deducir con certeza es un dato económico, el de las 750.000 entradas vendidas. Sin embargo, afecta de muy distinta manera esta cantidad de personas en los $3.325 \mathrm{~m}^{2}$ de la singular superficie expositiva de nuestro museo, que la cantidad de visitantes que pueda tener al año un museo de mucha mayor superficie, y/o diseñado con criterios museológicos. Es también a partir de esta cifra que se suele calcular la cantidad media de visitantes por día, resultando en nuestro caso 2.674 personas, cifra que no nos aporta ningún dato significativo, ya que la mayoría de los visitantes se concentra en ciertas franjas horarias, en verano y en días festivos. Por otro lado, los horarios intensivos de visitas que rigen especialmente durante el verano (abierto cada día, de 9h. a 20h. y de 22h. a Ih.) favorecen un tipo de degradación de las obras por uso del público, con más posibilidades de roces, golpes y condensación; además de someterlas a más horas de exposición a la luz, cuyos efectos sobre los colores y sobre ciertos materiales son irreversibles.

Dado que la limitación del número de visitantes es improbable por el momento, confiamos en que las acciones de conservación preventiva atenúen los efectos de este factor: además del control del clima en las salas, las obras están protegidas en sus marcos-vitrina sellados, en los que, actualmente, se mantiene un microclima incluyendo un agente regulador de la humedad relativa, el Art Sorb. En los casos en que las obras tienen un marco escogido por el propio Dalí, al que gustaban los marcos antiguos, las pinturas son encapsuladas en un marco de aluminio que queda encajado e invisible dentro del marco original.

Otro recurso preventivo importante, que se ha aplicado tanto a las pinturas como a la obra sobre papel, ha sido la protección con cristales especiales anti-reflejantes que garantizan una visión nítida de las obras (observar en F.I. la nitidez de estos cristales) y dotados de filtros para los rayos ultravioleta; esta medida queda reforzada por un riguroso control de la iluminación en las salas interiores, que, ante la imposibilidad de reducir el tiempo de exposición a la luz, limita su intensidad reduciéndola a los valores recomendados por las normas internacionales: 50 lux para papel y I50 lux para pintura, retrasando así la degradación de origen lumínico.

\subsection{Factores de degradación de la obra pictórica y medidas preventivas}

La conservación de la obra de Salvador Dalí depende de los siguientes factores: por un lado, su calidad técnica, en función de las diversas etapas de su actividad creativa, y, muy especialmente, de la historia de sus movimientos.
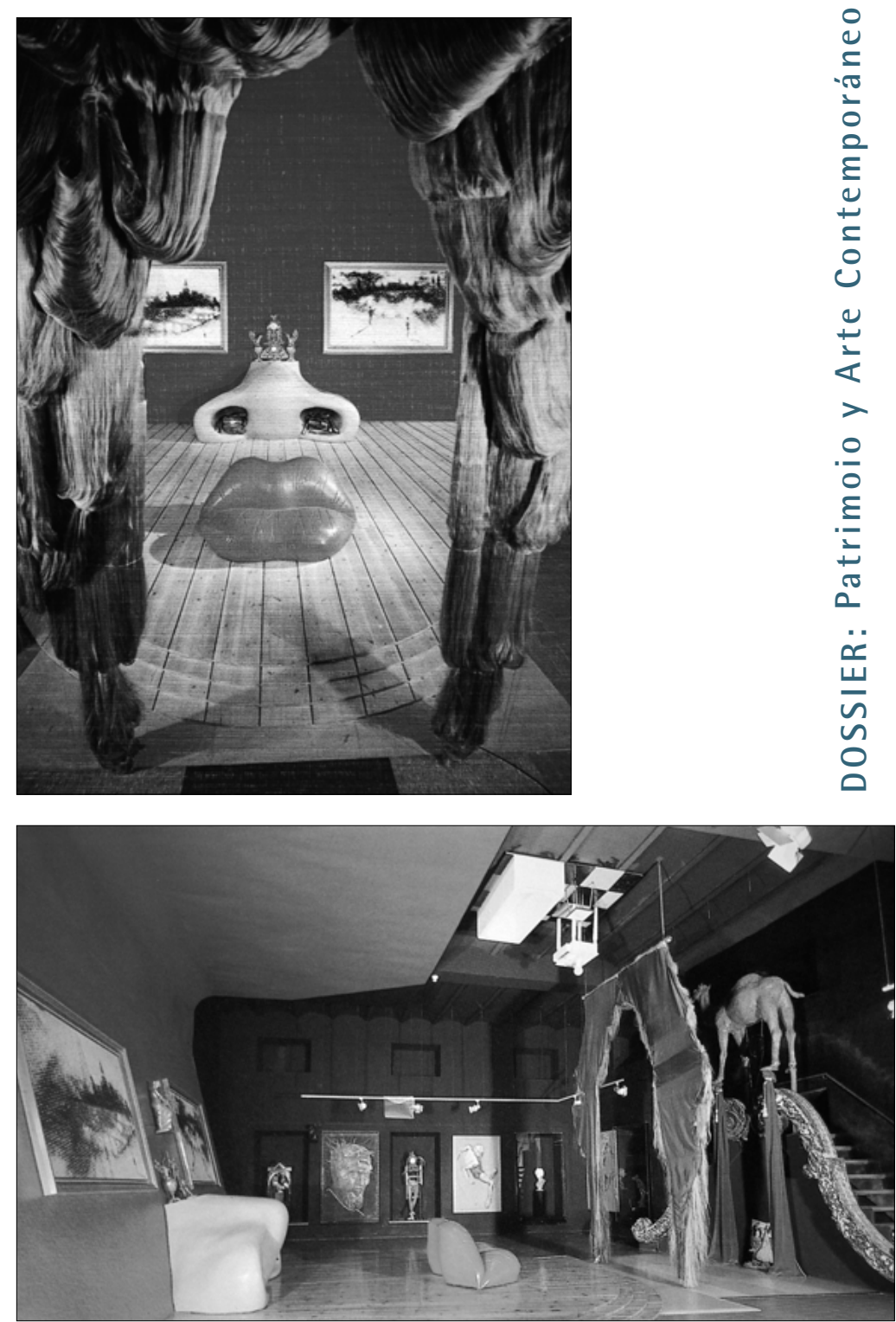

El movimiento de obras es una de las principales causas de su degradación, con sus repetidos transportes y manipulación, para participar a exposiciones nacionales e internacionales. Salvador Dalí ya era un artista internacional a principios de los años 30, moviendo sus obras por los circuitos establecidos para el arte moderno, alrededor de los polos que eran, y siguen siendo, París y Nueva York, habiéndose convertido en uno de los principales exportadores de exposiciones de este siglo: desde su primera exposición en Barcelona en 1925, hasta la inauguración de su museo en 1974, sus obras habían viajado por Europa y EEUU, participando en 124 exposiciones individuales y 148 exposiciones colectivas.

Es importante pensar en como podían ser los traslados de obras desde los años 30 hasta hace bien poco, cuando todavía no era fácil encontrar compañías de transportes especializadas en mover obras de arte, ni los medios de locomoción ofrecían las garantías de los de hoy en día, y ni siquiera existían los materiales modernos, especialmente los de amortiguación, con los que se preparan actualmente los embalajes.
5. y 6. La Sala de Mae West de frente y de perfil: la primera es la visión del público a través de una lente especial colocada en una lugar preciso de la sala, mientras que la segunda es la visión desde la entrada: como que el público no puede deambular por encima de la cara de por el estrecho paso delante de la peluca-cortina, contribuyendo a su paulatino desgaste. Mae West, solo puede "desfilar" 
Pero actualmente, a pesar de que las condiciones para el traslado de obras son mucho mejores, el incremento de la demanda de exposiciones en general, y de Dalí en particular, exige de la FGSD un constante movimiento de obras, que, en cualquier caso, acelera su envejecimiento.

Para hacernos una idea del ritmo de exposiciones temporales de la FGSD, hemos cuantificado el movimiento de obras para una exposición como la cantidad total de obras prestadas, multiplicada por sus dos traslados: el de salida a la exposición, y el de retorno a la Fundación, resultando, por ejemplo, que en 1998, la FGSD participó en 15 exposiciones, con 136 movimientos de obras; en 1999, fueron 10 las exposiciones, pero 696 movimientos de obra, y en 2000, con 17 exposiciones, se realizaron 522 movimientos de obras.

Para contrarrestar un poco los efectos de tanto movimiento, hemos conseguido que los responsables de la Fundación contemplen una nueva clasificación de las obras, complementaria a la de su estado de conservación: su disponibilidad. Así, cada obra tiene en su ficha una clave que indica si es "prestable", "no prestable", o bien, "prestable con condiciones", en función de su manejabilidad, fragilidad, formato, ubicación...

A partir de que se decide prestar una obra, se elabora una ficha de su estado de conservación a la salida, documentado con una fotografía en color $(18 \times 24)$, y se prepara para el traslado: siempre salen protegidas dentro de un marco-vitrina lo más sellado posible, con metacrilato con filtro anti-UV (nunca con cristal), y con un regulador de humedad relativa.

A pesar de todo, el estado de conservación de la obra pictórica de S. Dalí es, en general, bastante bueno, ya que este artista dedicó desde siempre una atención especial a la técnica, y es a partir de ésta y de sus condiciones de conservación, que distinguimos tres grandes etapas:

No siendo las más conocidas, sus obras de la época, entre 1914 y 1928 son, desde el punto de vista técnico, las más interesantes, ya que pertenecen a un período de renovación incesante: sus sucesivas inquietudes técnicas y estilísticas, que van desde el impresionismo hasta el cubismo, pasando del brillo del óleo al mate del temple, las técnicas mixtas sobre delgados cartones de gran formato, los cuadros matéricos con collage de arena, conchas o piedras... nos crean diversos problemas de conservación, presentación y manipulación. Al no ser las obras más solicitadas en la historia de Dalí, su estado de conservación es bastante bueno a pesar de su fragilidad. Sin embargo, algunas de ellas podrían presentar problemas por las vibraciones que comporta cualquier traslado, y a priori, la Fundación no las presta: entre ellas podríamos citar todas las pinturas matéricas sobre cartón o madera de los años 1926 a 1928, y los temples sobre cartón de 1923.

A partir de 1929, la pintura de Dalí entra en una evolución que culmina en 1940, con la decisión de profundizar en una técnica próxima por su materia a la de los cuadros holandeses del siglo XVII. El perfeccionamiento de esta técnica consiste en reproducir la realidad a base de una materia pictórica brillante y lisa, que deja ver raramente la pincelada, con la misma precisión de detalles que la de una fotografía.

Las dificultades propias de esta técnica, unidas a que son de este período las obras más conocidas de Dalí, las más viajadas y, por tanto, las más sometidas a condiciones de exposición discutibles, hacen que sea entre ellas donde se presentan más problemas de conservación y restauración.

Desde el punto de vista técnico podemos definir un tercer y último apartado, que empieza con el inicio del deterioro físico de Dalí en los años 60 y termina con su última pintura de 1983. Se trata en general de pinturas al óleo sobre lienzo, de diversos formatos, que no presentan problemas de conservación, principalmente porque no están muy castigadas, ya que al no ser las más representativas de Dalí, no suelen ser solicitadas para exposiciones. Entre ellas cabe destacar especialmente sus cuadros dobles para visión estereoscópica, por la corrección de su técnica hiperrealista, para los que cuenta cada vez más con la colaboración de un ayudante de taller que le prepara los lienzos según sus instrucciones. Tampoco presentan problemas de conservación las series dedicadas a Miguel Angel y a Velázquez, en las que encontramos un Dalí expresionista, que más que pintar, dibuja al óleo. Por fin, cierra este apartado, de manera coherente, su serie sobre la teoría de las catástrofes del matemático francés René Thom, que marca el fin de su actividad pictórica, que no creativa.

\section{Criterios de intervención}

A pesar de cuantas medidas preventivas se lleven a cabo, hay obras cuyo deterioro exige una intervención restauradora, y, en estos casos, los criterios dependen del tipo de obra, de la intención de Dalí y del lugar de exposición.

\section{I. Pintura}

En general, nuestras intervenciones han consistido en la fijación de zonas de pintura descohesionada, ya sea por problemas inherentes a la técnica del artista, ya sea por la historia de cada obra, como por ejemplo, por accidentes debidos a una mala manipulación, o a consecuencia de malas condiciones de almacenamiento o de exposición.

Siempre se ha dedicado una especial atención en no alterar el aspecto de los acabados del artista, que son muy particulares, ya que las zonas de brillo son irregulares, jugando con veladuras de resina ámbar para dar énfasis a ciertos detalles. Por ello, una de nuestras especialidades ha sido la de "restaurar restauraciones", eliminando en no pocas obras, barni- 
ces aplicados indiscriminadamente en anteriores restauraciones, que falsean el aspecto del original.

En cuanto a la reintegración pictórica de las lagunas, nos remitimos a la anécdota relatada al principio, ya que, cuando la restauración de Port Alguer hubo terminado, Dalí quiso verlo, aprobando implícitamente la utilización del "tratteggio" para reintegrar las lagunas pictóricas.

En algunas ocasiones es aconsejable la mínima intervención, como en el caso de la cesta del pan óleo sobre tabla $(33 \times 38 \mathrm{~cm})$ de 1945, por el que Dalí tenía tal devoción que nunca lo quiso prestar para ninguna exposición, colocándolo en el lugar preferente de la Sala del Tesoro. A pesar de ello, los movimientos de su sensible soporte de madera han provocado unas micro-fisuras verticales en su fondo negro, dejando a la vista la capa de preparación. Dado que la reintegración pictórica de las fisuras sobre el delicado negro mate del fondo sería más visible que dejarlas como están, se ha procedido a la fijación de las zonas afectadas, y a evitar en lo posible las condiciones que favorecían el movimiento del soporte, protegiendo la obra dentro de un marco de aluminio con micro-clima, encajado dentro del marco antiguo que escogió Dalí. Esta obra es objeto de un riguroso control periódico y, de momento, está estabilizada.

Existen obras, sin embargo, que, por sus características especiales, nos han obligado a realizar tratamientos no convencionales: sirva de ejemplo el sistema de presentación propuesto para la apoteosis del dólar, óleo sobre tela de $300 \times 400 \mathrm{~cm}$ pintada en 1965.

La FGSD adquiere esta obra en 1991, a pesar de que su estado de conservación no es óptimo: de dif́cil manipulación por sus dimensiones, esta obra había sido solicitada desde su creación en numerosas exposiciones por todo el mundo, y el resultado de los sucesivos clavados y desclavados del lienzo para poder transportarlo enrollado, así como un almacenamiento indebido (la tela había permanecido doblada durante largo tiempo) habían dejado secuelas: marcados pliegues verticales en tela y pintura, y los laterales, debilitados por tantos agujeros, ya habían sido reforzados por unas bandas de tela nueva que habían encogido, provocando aún más deformaciones en el soporte. El bastidor original había sido sustituido por un curioso modelo de hierro, al que la tela iba sujeta por medio de cuerdas. Para ello, habían colocado en las bandas laterales una serie de ojetes metálicos.

Aunque el proceso de esta restauración fue singular, sólo nos detendremos a considerar el innovador sistema de sujeción de la tela al bastidor para minimizar el inevitable desgaste de las bandas laterales, ya que la obra ya estaba solicitada en una exposición, y parecía ser que su futuro iba a ser muy movido.

Así, aprovechamos la idea propuesta en la restauración anterior de volver a colocar ojetes metálicos cada $8 \mathrm{~cm}$ en las nuevas bandas de tela. Pero esta vez, en lugar de tensarla con cuerdas, atornillamos la tela al bastidor.

El bastidor de hierro fue sustituido por uno de aluminio con tensión continua, que fue adaptado a nuestras necesidades: en el perfil de madera fueron introducidas cada $8 \mathrm{~cm}$., coincidiendo con los ojetes, unas roscas de latón destinadas a alojar los tornillos que fijarían la tela al bastidor.

Aunque este sistema dio un resultado excelente, la suerte de "la apoteosis del dólar" ha sido mejor, ya que, después de participar en la exposición para la que ya estaba comprometida, ha entrado a formar parte del grupo de obras "no prestables", y desde 1992 permanece expuesta en una de las salas nuevas del Teatro-Museo, sin presentar la más mínima deformación ni obligarnos a tensar la tela en todos estos años.

\subsection{Montajes e instalaciones.}

La conservación de objetos de todo tipo, ordenados en forma de montajes e instalaciones, es un aspecto cada vez más importante en la conservación de la obra de Dalí.
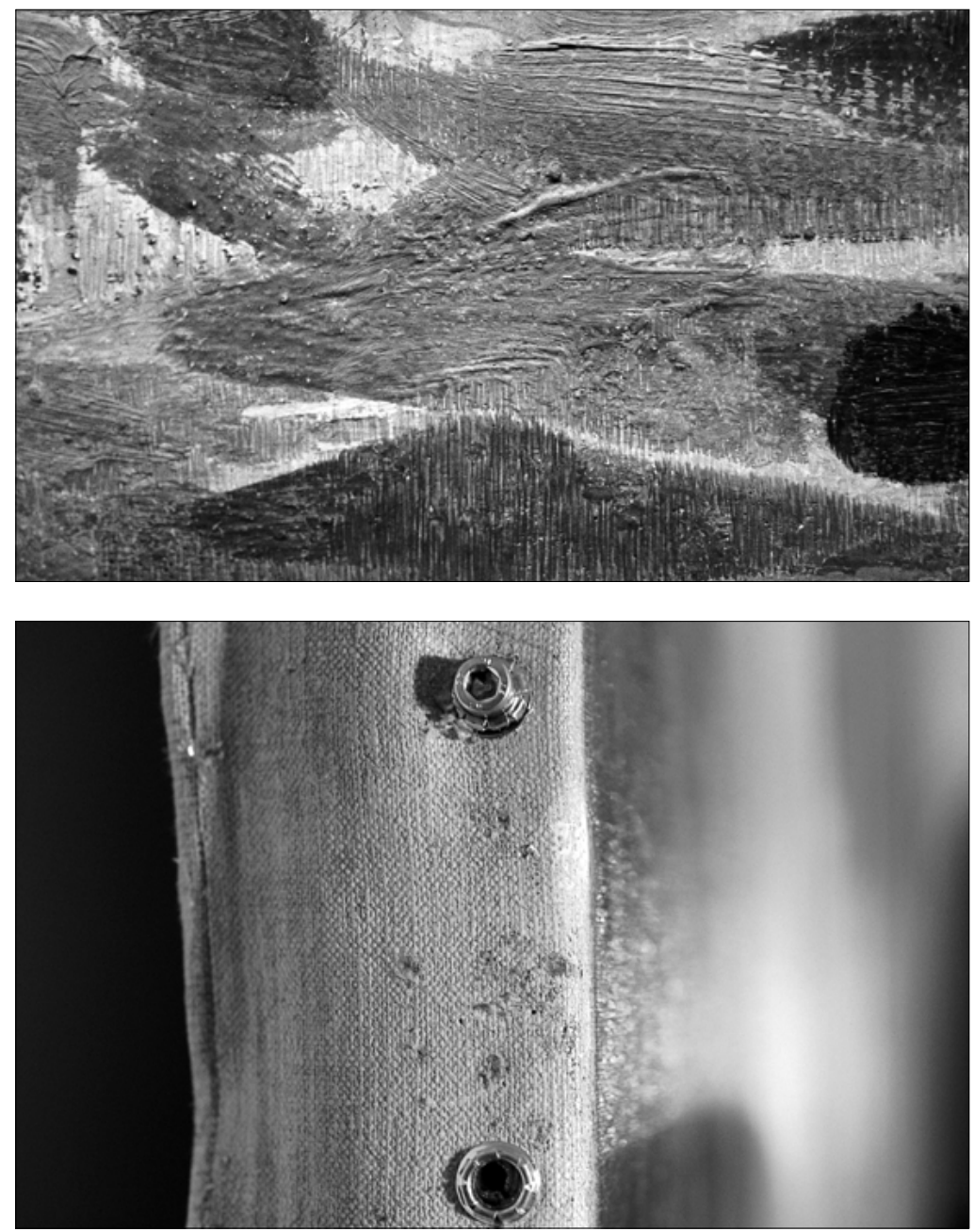

7. Detalle de "tratteggio" en "Port Alguer".

8. Detalle del sistema de sujeción de "La apoteosis del dólar",
con algunos tornillos colocados. 
La apertura al público de las casas de Port Lligat y Púbol ha obligado al Departamento de Conservación y Restauración a diversificar su esfuerzo para la conservación de la gran cantidad de objetos con los que Dalí escenificaba su vida cotidiana. Esto no presentaría problemas muy diferentes a los de cualquier casa-museo en la que se exhiben lugares y objetos relacionados con la vida de algún personaje célebre, si no fuera que en el caso de Dalí nos encontramos ante un artista "total" que llenaba de sentido estético todo lo que le rodeaba. Por esto, más allá del valor fetichista de las cosas que han acompañado al genio, se trata de conservar el espíritu que el artista quiso transmitir con esas cosas.

Dejando para mejor ocasión los problemas conceptuales de conservación de las casas, nos centraremos en algunos ejemplos prácticos de intervención en montajes realizados por Dalí especialmente para su Teatro-Museo, y que dividiremos en montajes de interior y montajes de exterior.

\subsubsection{Montajes de interior.}

Desde la creación del Teatro-Museo, el público circula por la Sala de Mae West, rozando la pelucacortina (ver F.6.), que ya ha sido "restaurada" en diversas ocasiones por el peluquero que colaboró en su creación, hasta que la degradación del pelo artificial ha hecho imposible el milagro: la peluca debía ser sustituida. Actualmente, un equipo de tematizadores está construyendo un armazón de poliéster que dará volumen al peinado de la actriz, y sobre el que fijarán pelo artificial. En las zonas de paso del público, se sustituirá el pelo por un cortinaje, más resistente al uso, y más acorde con el proyecto original de Dalí.

Es interesante mencionar en segundo lugar los montajes con movimiento (mecanismos que se accionan cuando el público introduce una moneda), a causa de su fragilidad. Un ejemplo de ello es el del Cristo desplegable, en la Sala de la Cúpula, que realizó Dalí expresamente para su museo en los años 70 , y que se exhibe dentro de una vitrina debajo del Torero alucinógeno (ver F.3.)): Dalí pintó sobre un trozo de tela el rostro de Cristo, que fue cosido a una túnica realizada con un pañuelo de Elisabeth Taylor. Esta figura está atada por sus brazos y piernas a una estructura metálica que, cada vez que alguien echa una moneda, se despliega y se vuelve a plegar, así que, cuando no está en movimiento, la figura de Cristo está comprimida.

Después de 20 años de funcionamiento continuo, de mancharse la figura con la grasa del mecanismo, y de quedar enganchada con sus aristas en sucesivas ocasiones, se decide por fin intervenir: se realizó una copia para el montaje en funcionamiento, renovable cada vez que fuera necesario, y se restauró el original que se exhibe al lado, estático, para que el público pueda apreciar tranquilamente la pintura original de Dalí, y el fetiche que supone un pañuelo de la Taylor.

\subsubsection{Montajes de exterior.}

El caso más complicado es el del Carro Naval, en el patio del Teatro-Museo (ver F.4.). En el interior del Taxi lluvioso llueve cada vez que el público echa una moneda a la máquina tragaperras: los tres maniquíes, así como el follaje de plástico de su interior, requieren un mantenimiento especial, que se efectúa periódicamente. Sin embargo, la mitad de la carrocería del Cadillac es actualmente poliéster, ya que no ha podido resistir tantos años de lluvia por dentro y por fuera.

En cuanto a la barca que corona este "assemblage", el público la ve a una distancia de más de 10 metros, lo que ha permitido efectuar una intervención dràstica para su conservación, ya que después de más de 15 años de estar a la intemperie, la madera estaba en un estado ruinoso: el interior es de poliéster, se le ha dotado de un desagüe, se han rellenado las zonas de madera perdidas con espuma de poliuretano, y se repinta con pintura para exteriores tantas veces como sea necesario, para que parezca recién salida del agua, como quería Dalí.

Paradójicamente, el tratamiento de esta barca es completamente distinto al de otra barca incluida en otro "assemblage", situado en la entrada de su casa de Port Lligat: "el ciprés que nace dentro de una barca".

Se trata de un laúd, embarcación tradicional mediterránea ahora en desuso, que le fue regalada a Dalí en los años 60 para que pudiera materializar este icono tan recurrente en su obra pictórica.

El estado de la barca era ruinoso, por estar más de 40 años al final de un camino que resulta ser un torrente cuando llueve, y porque el ciprés que tiene dentro no ha hecho más que crecer; a la gente siempre le ha gustado hacerse fotos dentro, y además, nunca había tenido un mantenimiento, por más que algún carpintero aficionado le había hecho unos añadidos burdos sujetos con tornillos "oxidables".

A principios del 2001, se encarga por fin su restauración a un equipo de restauradores especializados que proponen una intervención de tipo "arqueológico", eliminando todos los añadidos, limpiando la madera de barnices reticulados, impregnándola con un producto adecuado para maderas de exterior, y consolidando la estructura con la reposición de cuatro costillas del mismo tipo de madera, y sin reintegrar las partes perdidas que no afecten a la estabilidad del conjunto.

A modo de conclusión, los problemas y soluciones aquí apuntados son una simple muestra de cómo la conservación del arte contemporáneo ha debido adaptarse a los profundos cambios de la práctica artística en los últimos tiempos: nuevos materiales, nuevos procedimientos $y$, sobre todo, nuevas intenciones y nuevos significados. 


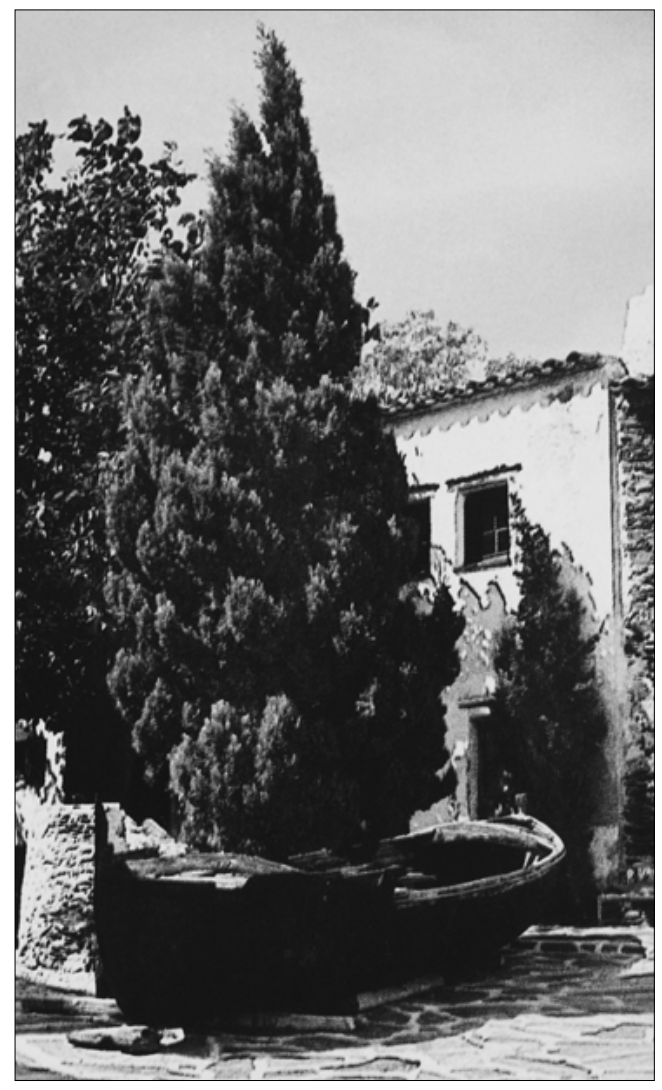

En la obra de Dalí y en sus museos se concentran elementos de las tendencias plásticas más relevantes del siglo XX; surrealismo, conceptual, pop, expresionismo y el resto de máscaras que ha adoptado el arte de los últimos ochenta años, aparecen como acordes de la sinfonía daliniana. El Departamento de Conservación y Restauración de la FGSD trata de

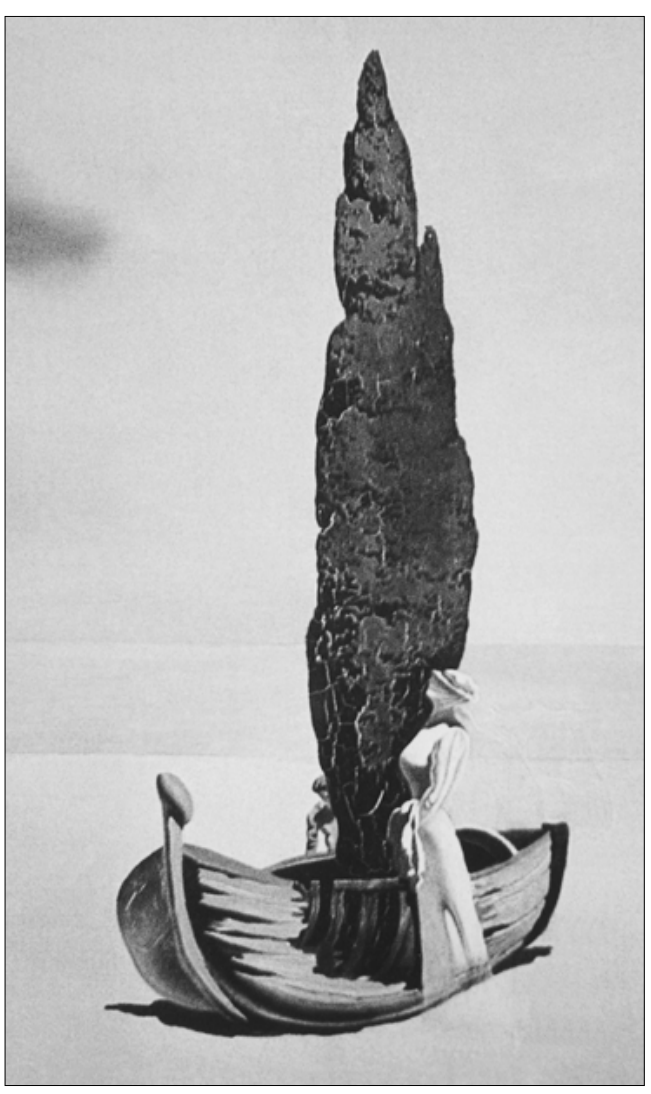

cumplir con el precepto fundacional de preservar la obra y el pensamiento de Salvador Dalí con todos los medios adecuados, más allá de los prejuicios y tópicos que han teñido la consideración de la obra daliniana, a cuya superación esperamos contribuir con nuestro trabajo, explicado someramente en este artículo.

\section{Bibliografía}

DALÍ DOMENECH, S. 50 secretos mágicos para pintar. Barcelona: Luís de Caralt, 1985.

DALÍ DOMENECH, S. Diario de un genio. Barcelona: Tusquets, 1988.

DALÍ DOMENECH, S. Vida Secreta de S. Dalí. Barcelona: Empúries, 1993.

DALÍ DOMENECH, S. Confessions inconfessables. Barcelona: Bruguera, 1975.

DALÍ DOMENECH, S. SI. Esplugues de Llobregat: Ariel, 1977.

DALÍ DOMENECH, S. Los cornudos del viejo arte moderno. Barcelona: Tusquets, 1990.

DALÍ DOMENECH, S. L'alliberaments dels dits. Barcelona: Quaderns crema, 1995.

DALÍ DOMENECH, S. Un diari 1919-1920: les meves impressions i records íntims. BCN: Edicions 62, 1994

DESCHARNES, R. Dalí, la obra y el hombre. Lausane: Edita, 1984.

DESCHARNES, R./ NERET, G. Salvador Dalí, 1904- 1989. Köln: B. Taschen, 1994

GÓMEZ DE LA SERNA, R. Dalí. Madrid: Espasa Calpe, 1985.
GIMÉNEZ FRONTIN, J.L. Teatre Museu Dalí. Barcelona: Tusquets, 1994.

GIBSON, I. La vida desaforada de S. Dalí. Barcelona: Anagrama, 1998.

ROMERO, L. Todo Dalí en un rostro. Barcelona: Blume, 1975.

STOLOW, N. The Microclimate: A Localised Solution. Museum News, Vol..56, n², Nov. Dec.1977, p.52-63.

LAFONTAINE, R.H. Silicagel. Technical Bulletin n I0. C.C.I., Otawa, 1984

THOMSON, G. Museum Environment. Butterworths, 1978.

DE GUICHEN, G. Climat dans les musées: mesure. ICCROM, 1984.

MERVIN, R./ MECKLENBURG, M.F/ MERRILL, R.M. Art in Transit. Handbook for Packing and Transporting Paintings. National Gallery of Art, Washington, 1991.

BERGER, G.A. Unconventional Treatments for Unconventional Paintings. Studies in Conservation 21, 1976, p. II5-128.

BERGER, G.A. More Unconventional Treatments for Unconventional Art Studies in Conservation 35, 1990
9. y 10. Foto de los años 70, antes de la realización del "assemblage", con el laúd antes de ser encajado en la base del ciprés, y detalle del óleo "Aparición de mi prima Carolineta en la playa de Rosas", de 1934, con una barca de aspecto ruinoso, como una premonición de cómo acabaría el monumento emblemático de la casa de Port Lligat. 